\title{
El amor como resistencia, en búsqueda de la dignidad latinoamericana
}

Love as a Resistance: looking for Latin-American dignity

\section{O amor como resistência: em busca da dignidade latino-americana}

Matilde Moros

Recibido: 31 de julio de 2013 Aprobado: 14 de mayo de 2014

Resumen:

Desde la perspectiva de la ética cristiana y hacia una ética de la dignidad, revisamos el llamado a una metodología descolonial y la forma como la subjetividad latinoamericana ha sido formada desde un cristianismo y una imaginación que, desde la conquista, han tenido un carácter colonizador. Los métodos culturales de resistencia, desde las comunidades, llevan siglos en pie. Estas mismas luchas son las que, desde nuestras teologías liberacionistas, también hemos afirmado como nuestras. A partir de la literatura y de sus famosos autores, como García Márquez, entendemos que la poesía y nuestra soledad latinoamericana son herramientas teológicas para nuestro tiempo. Esta soledad y el alma colonial, de la que nos habla la teóloga Marcella Althaus-Reid, nos llevan a cuestionar las moralidades decentes que nos fueron impuestas desde hace siglos y que, como nos afirman Walter Mignolo y Enrique Dussel, dieron inicio a la época moderna, a su ideología y a su economía del poder. Esta mentalidad de jerarquías hegemónicas, en la que el sujeto latinoamericano y su cristianismo particular se encuentran, busca descolonizarse con base en sus historias y en sus luchas concretas, desde cuerpos 
concretos y sexualidades concretas; pero es desde la poesía y la teología, basadas en el amor propio y el amor al prójimo, que entendemos cómo es que nuestra propia imagen nos causa, tanto la urgencia de lucha hacia soluciones dignas, como temor de nosotros mismos.

\section{Palabras claves:}

Descolonización, resistencia.

\section{Abstract:}

From a Christian ethical perspective and toward an ethic of dignity, in this article we review the call for a decolonial methodology and the way Latin American subjectivity has been shaped from Christianity and an imagination that, since the conquest, have had a colonizing character. Cultural methods of resistance from communities have been standing up for centuries. These are the same struggles that, from the liberationist theologies perspective, have also been affirmed as ours. From literature and famous authors such as García Márquez, we understand that our Latin American poetry and solitude are theological tools for our time. This loneliness and colonial soul, theologian Marcella Althaus-Reid talked about, lead us to question the decent morals that were imposed on us for centuries and initiated the modern era, its ideology and its economy of power, as Walter Mignolo and Enrique Dussel say. This mentality of hegemonic hierarchies, where Latin
American subject and his particular Christianity are based on, is trying to decolonize based on its stories and concrete struggles, from concrete bodies and concrete sexualities. But it is through poetry and theology, based on self-love and love of neighbor, that we understand how our own image causes us both the urgency of fighting for dignified solutions and the fear of ourselves.

\section{Key words:}

Decolonialization, resistance.

\section{Resumo:}

Na perspectiva da ética cristã e para uma ética da dignidade, revisamos o chamado a uma metodologia descolonial e a forma como a subjetividade latino-americana tem sido formada a partir de um cristianismo e uma imaginação que, desde a conquista, têm assumido um caráter colonizador. Os métodos culturais de resistência, a partir das comunidades, há séculos estão em pé. Estas mesmas lutas são as que, a partir de nossas teologias libertadoras, também temos afirmado como nossas. A partir da literatura e de seus famosos autores, como García Márquez, entendemos que a poesia e nossa solidão latino-americana são instrumentos teológicos para nosso tempo. Esta solidão e a alma colonial, da qual nos fala a teóloga Marcella Althaus-Reid, nos levam a questionar as moralidades decentes que nos foram impostas há séculos e que, como nos afirmam Walter Mignolo e 
Enrique Dussel, deram início à época moderna, à sua ideologia e à sua economia do poder. Esta mentalidade de hierarquias hegemônicas, na qual o sujeito latino-americano e seu cristianismo particular se encontram, busca descolonizar-se com base em suas histórias e em suas lutas concretas, a partir de corpos concretos e sexualidades concretas; mas é a partir da poesia e da teologia, baseadas no amor próprio e no amor ao próximo, que entendemos como é que nossa própria imagem nos causa, tanto a urgência de luta para soluções dignas, como temor de nós mesmos.

Ahora, pues, permanecen estas tres virtudes: la fe, la
esperanza y el amor. Pero la más excelente de ellas es
el amor.

(1 Corintios 13:13)

"Vamos a andar, en verso y vida, para llegar... con todas las banderas trenzadas de manera que no haya soledad"

Silvio Rodríguez

El amor poderoso que hemos aprendido de los teólogos desde hace siglos nos es presentado como una virtud. Es la base para toda resistencia cristiana; es la fuerza que, en la fe y la esperanza, llevamos adelante. San Agustín, de acuerdo con las ideas expuestas por Arendt, afirmó que el amor es un apetito, una moción. Y toda moción nos lleva hacia algún lugar. Ese apetito y esa moción están basados en lo que conocemos, como el bien. Por esta razón, el amor es una fuerza que nos conduce hacia a él; es la base de lo que hacemos para el bien común; ese bien común es lo que buscamos por medio de la ética de la dignidad humana ${ }^{89}$.

Por otro lado, la muerte -no el miedo a la muerte- fue lo que afectó profundamente a San Agustín, como podemos constatar en Confesiones. Y así como en la vida de San Agustín, también

89 Arendt, Hannah. Love and Saint Augustine. Chicago: University of Chicago Press, 1996. 
en nuestras vidas las experiencias cruciales nos llevan a entender que para resistirlas, es preciso que el amor sea nuestra base.

Algunas experiencias cruciales como la muerte de nuestros amigos y familiares más cercanos, o aun la de quienes consideramos nuestros hermanos en América Latina: tantas muertes y desapariciones ocurridas en múltiples procesos violentos en todos nuestros contextos inmediatos.

Porque si la vida es buena, y el temor a la muerte es malo, entonces para vivir la buena vida, lo único que nos queda es afirmar como cristianos que la vida es eterna, que en nuestra muerte no afirmamos finitud, sino vida eterna. Para alcanzar ese estado debemos vivir con amor, con fe y esperanza, confiando en que la justicia de Dios, también la libramos por medio del amor.

Pero aun desde la fe, la esperanza y el amor, somos llamados a la verdad, en nombre de la justicia, y entonces nos preguntamos: ¿cómo podemos prestar atención a la multiplicidad de violaciones que vivimos a diario en nuestro continente? En un continente, que con el pasar de la historia ha sido plagado por la muerte, la violencia y la soledad, ¿cómo buscamos ejemplos de resistencia basados en el amor? Y, al resistir el miedo, ¿cómo nos urge el amor? ¿Cuál ética, qué método, qué forma de vivir promovemos? ¿Cómo es que debemos reponernos de tantas indignidades? El famoso trovador, Silvio Rodríguez, ha descrito nuestra dignidad en una reconocida canción titulada Al final de este viaje: "quedamos los que puedan sonreír en medio de la muerte, en plena luz". Así que, sonriendo y amando, busquemos juntos cómo es que resistimos, cómo es que luchamos por conseguir la vida y la justicia desde el amor.

De los días de mi niñez, recuerdo una costumbre que me marcó para toda la vida. En los Andes venezolanos, la gente, al encontrarse con sus amigos, procedía a saludarse con la siguiente 
expresión: “¿Qué hubo poeta?” Así que, basándome en esta experiencia, propongo que cuando nos saludemos con esta frase, nos sintamos en tierra de amigos, en América Latina, un espacio conocido por su poesía y el amor profundo que en esa poesía nos ha dejado su recuerdo. Después de todo, cuando uno de nuestros grandes escritores, Gabriel García Márquez, aceptó el Premio Nobel de Literatura, habló de nuestra historia triste, nuestra soledad, la violencia que consume nuestra realidad y la magia de nuestra poesía:

La poesía que con tan milagrosa totalidad rescata a nuestra América en las Alturas de Machu Pichu de Pablo Neruda el grande, el más grande, y donde destilan su tristeza milenaria nuestros mejores sueños sin salida. La poesía, en fin, esa energía secreta de la vida cotidiana, que cuece los garbanzos en la cocina y contagia el amor y repite las imágenes en los espejos. ${ }^{90}$

La energía secreta, como dice García Márquez, contagia el amor y repite imágenes en los espejos, ¿pero de qué imágenes habla? Imágenes del amor contagiado de la energía de la poesía, de ahí parte la resistencia contra los poderes de la muerte.

Si nuestra identidad como latinoamericanos se define a partir de la poesía, esto supone que viene acompañada de imaginación. En Comunidades Imaginadas ${ }^{91}$, Benedict Anderson apuntó que más alla de teorías políticas, y a partir de una teoría antropológica, que la imaginación es lo que él encuentra en el nacionalismo, en ello se basa la formación de una determinada comunidad, es decir, toda comunidad se basa en una imaginada y compartida imagen de sí misma.

90 García Márquez, Gabriel. (1982). La Soledad de América Latina (Discurso de aceptación del Premio Nobel 1982).

91 Anderson, Benedict. Imagined communities: reflections on the origin and spread of nationalism. London; New York: Verso, 1991. 
Cuando Walter Mignolo escribió sobre el proceso descolonial en La idea de América Latina ${ }^{92}$, apreciamos que las comunidades, sean naciones o continentes enteros (Latinoamérica), se entienden a partir de la imaginación y de un conjunto de ideas que nos fueron impuestas. La idea de la descolonización a la que nos llama Mignolo en América Latina, es también un llamado que Enrique Dussel nos lanza repetidamente. Descolonizarnos es un llamado a comprender, desde nuestra relación con el otro, por qué América Latina fue formada desde una idea que presenta a esta tierra como el espacio ideal que puede ser manipulado y ocupado por individuos ajenos (el otro). Marcella AlthausReid también presta atención a este problemática en La teología indecente cuando se refiere al proceso de resistencia, en el que tomamos nuestras imágenes más íntimas de "almas coloniales”, lo que nos corrompe la decencia imaginada. Para ella, descolonizar no es solo una meta, también consiste en un método de resistencia a esa soledad que nos ha traído tanta violencia. Por ello, el método sirve primero para contar nuestras historias sexuales, nuestras historias de cuerpos concretos y la violencia desmedida que han tenido que soportar, y de esta manera, poder imaginar otro mundo donde las realidades sean amorosas y no "historias de amor" violentas.

A esto, almas coloniales de historias de amor violentas, también unimos las imágenes descritas por García Márquez en su discurso, donde expuso cómo hemos sido vistos los latinoamericanos a lo largo de la historia :

Antonio Pigafetta, un navegante florentino que acompañó a Magallanes en el primer viaje alrededor del mundo, escribió a su paso por nuestra América meridional una crónica rigurosa que sin embargo parece una aventura de la imaginación... Contó que al primer nativo que encontraron

92 Mignolo, Walter. 2005. The idea of Latin America. Oxford: Blackwell. 
en la Patagonia le pusieron enfrente un espejo, y que aquel gigante enardecido perdió el uso de la razón por el pavor de su propia imagen...Este libro...no es ni mucho menos el testimonio más asombroso de nuestra realidad de aquellos tiempos...Los Cronistas de las Indias nos legaron otros incontables...La independencia del dominio español no nos puso a salvo de la demencia... Poetas y mendigos, músicos y profetas, guerreros y malandrines, todas las criaturas de aquella realidad desaforada hemos tenido que pedirle muy poco a la imaginación, porque el desafío mayor para nosotros ha sido la insuficiencia de los recursos convencionales para hacer creíble nuestra vida. Este es, amigos, el nudo de nuestra soledad. Pues si estas dificultades nos entorpecen a nosotros, que somos de su esencia, no es difícil entender que los talentos racionales de este lado del mundo, extasiados en la contemplación de sus propias culturas, se hayan quedado sin un método válido para interpretarnos. Es comprensible que insistan en medirnos con la misma vara con que se miden a sí mismos, sin recordar que los estragos de la vida no son iguales para todos, y que la búsqueda de la identidad propia es tan ardua y sangrienta para nosotros como lo fue para ellos. La interpretación de nuestra realidad con esquemas ajenos solo contribuye a haceros cada vez más desconocidos, cada vez menos libres, cada vez más solitarios... Sin embargo, frente a la opresión, el saqueo, y el abandono, nuestra respuesta es la vida... Ni los diluvios ni las pestes, ni las hambrunas ni los cataclismos, ni siquiera las guerras eternas a través de los siglos de los siglos han conseguido reducir la ventaja tenaz de la vida sobre la muerte. ${ }^{93}$

Si no supiéramos que fue García Márquez quien pronunció este discurso, quizá pensaríamos que podría tratarse de un texto bíblico escrito por un profeta, un cronista o un evangelista, pues pone en evidencia a Dios, la vida en su complejidad y la esencia poética de nuestras almas, de nuestra identidad en medio de la diversidad de donde hemos partido y a donde hemos llegado.

93 García Márquez, Gabriel. (1982). La Soledad de América Latina. 


\section{SIXỐ ? Volumen 7, Número 2, 2013}

Pero este texto latinoamericano que tenazmente afirma la vida sobre la muerte, es también una afirmación del amor profundo que sentimos por la vida, por la comunidad, por nuestra imaginación, que tiende a llevarnos más allá de la realidad. Es desde este amor que hemos resistido a ser medidos con varas iguales o parecidas a las medidas aplicadas a otras zonas y pueblos.

Es desde el amor, la imaginación y la tenacidad por la vida que hemos creído en el devenir de nuestros pueblos, en la transformación de nuestro presente hacia un futuro digno, más allá de toda humillación y de toda violación de nuestro ser. Pero miremos también qué otro tipo de imaginación es puesta en evidencia en este discurso, ya sea por su semejanza con un texto bíblico o por las consecuencias de la violencia vivida a diario por nuestros pueblos.

Si es cierto que nuestra imaginación nos hace poetas y nos permite mirarnos como tenaces luchadores por la vida, también es cierto que algo de la soledad latinoamericana nos ha sido dictada con la imaginación de otros pueblos que primero nos vieron como gigantes enardecidos y luego decidieron desplazarnos hasta convertirnos en el otro; de estos pueblos, ubicados en otros continentes, emigraron poblaciones enteras , algunas para dominar y otras para vivir como esclavos. Tanta mezcolanza y tanta división nos dejó con poblaciones separadas por etnias y razas, imaginadas desde fuera de nuestra realidad, además de hegemonías de mestizajes dictadas hacia adentro, hasta el punto que hemos creído que no somos ni blancos, ni indígenas, ni negros, sino algo nuevo, capaz de borrar todo elemento cultural y producir una nueva realidad. Pero a veces, ante lo que vemos en el espejo, ante nuestra propia imagen, también reaccionamos con locura, igual que el gigante de la Patagonia descrito por el cronista que viajó con Magallanes. Nuestra imagen refleja no solo lo imaginado, sino también espectros que, pensamos, habían sido borrados, 
e imágenes que no quisiéramos olvidar porque forman parte de nuestra vida cotidiana.

Enrique Dussel, en un corto texto filosófico sobre el racismo en América Latina, afirma que tanto el racismo, como el machismo, es una ideología. Toda ideología cumple un círculo práctico con la estructura económica y política, y parece ser frecuentemente confirmada con cualidades accidentales; por ello se puede descubrir que el "misterio del racismo, que a pesar de aparentemente estar situado al nivel psicológico (resentimiento, desprecio, deficiencia, agresividad, sado-masoquismo, etc.), en realidad su origen está en otro nivel (tanto histórico como estructural)"; ${ }^{94}$ pues para entender esas imágenes y estructuras impuestas como ideologías tenemos que comprender que, tanto en el plano histórico como estructural la identidad latinoamericana fue fundada con base en una serie de violaciones e intercambios políticos, económicos y religiosos, es decir, la economía de la dominación de unos sobre otros es evidente, pero ¿cómo es que está compuesto el círculo práctico de esta ideología?

Dussel nos explica que hay muchas posiciones o perspectivas que nos ayudan a entender esta ideología. Por un lado, aparece el "economicismo", como aquella ideología de la dominación, donde el racismo equivale a la mano de obra. Por otro lado, el psicologismo subjetivista "niega toda posibilidad de pensar el tema por parte de quienes sufren la humillación y discriminación en su propia 'piel'95. Estos dos polos absolutizan la ideología a una forma de apreciación.

Quizá la perspectiva que mejor conocemos es la del racismo "biologista", la más utilizada en los procesos de creación de nuevas naciones a lo largo de nuestra historia, circundada por períodos

94 Dussel, Enrique. "Racismo, América Latina Negra y Teología de la Liberación”, Petrópolis: Vozes, N. ${ }^{\circ} 76,1982.485$

95 Idém. 
de conquista y colonización. Este racismo o desintegración de los pueblos se basa en supuestas divisiones naturales que obedecen a un conjunto de superficialidades como el color de la piel; esto se asimila al machismo "biologista" que, también, es una especie de fragmentación basada en supuestas divisiones naturales que le otorgan superioridad a un conjunto de individuos. Todo esto nos lleva a entender que el racismo se sitúa como ideología a través de la historia de nuestro Continente. ${ }^{96}$

Esta ideología sobrevive en nuestras más íntimas relaciones, en nuestros hogares, en nuestras labores; y está basada en la violación de nuestra humanidad, de nuestros cuerpos, de los derechos humanos, la violencia sexual, las divisiones de clase, raza y género; también en la violación de nuestros sueños, de la poesía y de la vida que tanto afirmamos.

En nuestra intimidad, desde hace siglos, hemos imaginado y creado una moralidad formada a la semejanza de esta ideología y de las teologías medievales que resaltan la superioridad masculina, cristiana, y europea (blanca). Y para los individuos que dentro de esta ideología son vistos como seres superiores, los poderes de esos grupos basados en la hegemonía de una raza creada de forma repentina, aunque en nuestra soledad esa hegemonía (dominantes- dominados) ha sido imaginada y organizada desde la modernidad (hace quinientos años aproximadamente).

Mignolo y Dussel sostienen que con nosotros comenzó la modernidad; pero propongo que la modernidad, aunque se forjó con imágenes subyacentes, también las imágenes fueron forjadas en cuerpos concretos según lo indica Peter Wabe en Raza y sexo en América Latina; estos representan hibridismos motivados en cuerpos de mujeres, masculinidades y feminidades hetero-sexistas creadas a partir de las relaciones entre hombres y mujeres

96 Ibíd., 486. 
indígenas y africanas, de pueblos colonizados a la fuerza, esas imágenes se relacionaron con una brutal fuerza militar, espiritual y corporal ${ }^{97}$.

La crisis europea que creó la imagen de un sujeto humillado, creó también, un sistema de raza y género basado en jerarquías cristianas de pureza y vida eterna marcadas por la conquista de América y sus habitantes (antiguos o nuevos). La impureza, la muerte y la enfermedad fueron asociadas con los cuerpos de mujeres no europeas, y de sus hijos mestizos y mulatos nacidos para convertirse en trabajadores explotados. Antes de las grandes inmigraciones en la modernidad, fueron las poblaciones esclavizadas quienes recibieron esas primeras imágenes forzadas, no desde el amor, ni la poesía, sino desde lo opuesto, que corresponde a la máxima humillación del ser humano, el no ser visto como persona. Sabemos de los debates teológicos entre Las Casas y Juan Ginés de Sepúlveda, estos europeos habían vivido entre pueblos moros y judíos, antes que el cristianismo fuera la ideología que dominara las distintas concepciones del español o el portugués. Por ello, la mezcla de las ideologías dominantes que prevalecían dentro y fuera de la iglesia contribuyeron a la formación de los nacionalismos. Basta aclarar que no fue únicamente esa ideología basada en la imagen de la diferencia lo que nos formó y sigue formando.

¿Y la dignidad? Si existe la humillación extrema en nuestra formación también podemos hablar de dignidad. Desde los hijos de los pueblos originarios, y los hijos de los pueblos de ascendencia africana recibimos métodos de resistencia contra la violación, la humillación y la imaginación .

Las economías imperiales, creadas primero desde la violación de poblaciones indígenas y africanas, hasta la violación de culturas, gobiernos, tierras y almas, continúa en vigencia, y se multiplica

97 Peter Wade. Race and sex in Latin America. 


\section{SIXÔ ? Volumen 7, Número 2, 2013}

junto con las economías globalizadas desde las perspectivas de aquellos que se creen los dueños de la tierra y de la historia. La discrepada identidad de Latinoamérica, según García Márquez, afirma la vida, aun desde la muerte.

Leamos esta realidad a partir de las novelas de García Márquez, pues más allá de Cien años de soledad, tenemos otras obras destacadas como El amor en los tiempos del cólera y Del amor y otros demonios, que describen nuestras realidades y moralidades basadas en una ética dominante que ha convertido el amor en una forma de gobernarnos medida en jerarquías, en costumbres y valores, basados en lo que según hemos creído, correspondía a lo racional, correcto, y en orden. Pero la crítica que ha hecho García Márquez en El amor en los tiempos del cólera se centra en que el caos que nos rodea, cual época de enfermedad, no se acomoda a estos ordenes basados en los miedos a la aventura, la imaginación y la pasión por la vida. Al contrario, los amores entre amantes en esta novela representan ese "tenaz amor por la vida" que nos acompaña durante toda nuestra existencia. Por otro lado, en El amor y otros demonios apreciamos la representación femenina de América Latina convertida en una niña del Caribe, que aunque es hija de miembros influyentes de la sociedad, es criada entre esclavos y forma parte de múltiples mundos religiosos, culturales y sociales. Este personaje es visto como una amenaza por el mundo dominante; además, al encontrarse con "otros" es concebida como un ser despreciable cubierto por la enfermedad. En la novela es la "rabia" la que produce el miedo, y ella es una posible infectada tras la mordida de un perro callejero. Este "perro" se asemeja a la mujer de Canaán que le dice a Jesús que aun los perros comen las migajas de los señores, pero en esta instancia los señores y las señoras terminan castigando a la niña excluida. La pobre princesita de los cabellos rojos, termina en un convento, con ochenta de las jóvenes más influyentes, que son monjas, entre ellas, las encargadas del convento, y otras 
encargadas de la moralidad decente; finalmente, la niña termina siendo exorcizada y amada a la misma vez por la poesía de un religioso, el sacrificio máximo de nuestra historia, que según García Márquez, la ética dominante dicta que está llena de demonios, siendo el amor uno de ellos.

Pero seamos específicos al decir que el amor es también como un demonio que nos posee, nos hace ver cosas que no están y nos llena de pasión para imaginar más allá de la realidad; cuando desde el amor organizamos la resistencia, ¿cómo lo reconocemos? Si lo que hemos conocido ha sido una ética basada en valores, reglas y moralismos que nos ha mantenido, por siglos, sumidos en la violencia, ¿acaso no ha existido otra ética? La ética de la dignidad, que se basa en una resistencia desde el amor, es la ética liberadora, trabajada desde la comunidad que, como muestra la Teología de la Liberación, irrumpe desde la mirada de los desposeídos, de los pobres. Tantos que hemos visto trabajar desde la urgencia, desde la impaciencia, desde la búsqueda de otro mundo, han demostrado cierta manera de ver el cosmos, que en nuestros estudios sociológicos ahora sabemos que no es cosa nueva, ni inventada por los liberacionistas, es cuestión de forma de vida, de organización social en el nivel de mujeres, de grupos de comunidades fuera de la dominación, sobreviviendo puramente desde el amor. O sea, si es la vida digna lo que se busca, hemos de mirar cómo es que desde los más despreciados hemos visto ejemplos de lucha no para el poder, sino para la liberación. Sin caer en romanticismo, sino al contrario, abrir los ojos y ver cómo es que ciertas formas de organizarnos en comunidad son muy particulares y nos pueden ayudar en este amor por la vida digna.

He buscado estudiar un caso de organización de mujeres, en particular el de una mujer líder en mi país, Venezuela. Por ello, he revisado varias investigaciones de Iraida Vargas Arenas (socióloga), quien ha estudiado la organización y la resistencia de 
mujeres en Venezuela, comenzando con las rebeliones y sublevaciones de esclavos negros entre 1525 y 1799, Vargas Arenas revisa cuidadosamente los estudios de otros expertos en esos procesos y ve evidencias de esas rebeliones en "la estructuración de los sectores populares contemporáneos, (y) que el cimarronaje, si bien estuvo compuesto principalmente por los esclavos de origen africano que huían, también incluyó a muchos indígenas que pasaron a vivir en los cumbes y a combatir activamente a los opresores" ${ }^{98}$ La rebelión de los pobres, los desposeídos, las mujeres, los esclavos, en otras palabras, de estos hijos de la conquista y la colonia, quienes se convierten en "los sectores populares", nos muestra cómo es que debemos de mirar las estrategias de lucha contra la violencia que impera en nuestro continente.

Argelia Laya, una mujer del siglo XX, nacida en 1926 y luchadora hasta su muerte en 1998, es el caso que he estudiado, para evidenciar como la estructuración de procesos más contemporáneos puede ser también herencia de otros tiempos. Fue Argelia Laya quien insistió que sin las mujeres no había cambio social para todos. Ella promovió una lucha desde la negritud y el feminismo, ambos términos y realidades eran tabúes en la Venezuela de antaño, y quizá, todavía. Además, desde mi perspectiva de ética cristiana, lo que muchos no saben de ella fue que se identificó con múltiples valores que se evidenciaron en su liderato en la Iglesia, cuando fue presidenta de los jóvenes presbiterianos.

Asimismo, su identificación con el pueblo durante el período dictatorial la condujo a convertirse en la "comandante Jacinta" en la guerrilla venezolana de esa época. Después de la amnistía, Argelia fue líder del partido MAS, y fue candidata a la presidencia del Movimiento al Socialismo. Pero fue la lucha por los derechos humanos que impactó el legado de su lucha política y específicamente, la lucha por cambiar leyes para proteger a las

98 Vargas Arenas, Iraida. Resistencia y participación. Caracas: Monte Ávila, p. 64. 
mujeres lo que realmente fue su legado. Argelia Laya, las misma, quien dejó en Venezuela las 'casas de la mujer', una institución para aquellas mujeres que habían sido desplazadas por la violencia doméstica, además de muchos otros cambios de leyes y posturas, fue quien dijo:

Los derechos humanos son los derechos fundamentales de los hombres y mujeres, de los niños y de las niñas vistas desde una perspectiva de género. El no reconocimiento a la violación de los derechos económicos, sociales, culturales, civiles y políticos de las mujeres es una práctica androcéntrica ejercida a través de la violencia visible (física y sexual) y/o por medio de la violencia invisible (cultural, social, política y legal). Históricamente la sociedad ha negado hasta hoy la condición de sujeto activo a la mujer, confiriéndole la pasividad como rasgo típicamente femenino. Sin embargo, la pasividad absoluta es ausencia de vida. Y en la cotidianidad las mujeres son sujetos históricos activos que experimentan variadas y complejas vivencias a lo largo de su existir desde la niñez hasta la ancianidad. Desde su visión de género perciben el mundo con una óptica complementaria (que no excluyente) a la del hombre, con una perspectiva propia; ambas formas de percibir la realidad si se actúa en un plano de igualdad y solidaridad, contribuyen a enriquecer a los seres humanos en el compartir de la existencia y rehumanizar la sociedad. ${ }^{99}$

Así, la herencia de Argelia Laya, nos demuestra el amor en acción, la imaginación de otro mundo posible, y la resistencia de siglos reproducida en cambios concretos para cuerpos concretos. ¿Qué otros movimientos sociales-movimientos desde la espiritualidad y la vivencia de los pueblos originarios, de pueblos afrodescendientes, de pueblos construidos por la mezcla de herencias, por mujeres y hombres, por organizaciones que imaginan otro mundo-podemos identificar? ¿Cuáles serían los requisitos

99 Laya, Argelia. Fronesis. Vol. 5, N. ${ }^{\circ} 3$ (1998), 117. 
que nos permiten entender los métodos para afirmar la vida en medio de la muerte? ¿ Qué significa una vida digna en nuestro continente? Habrá tanto hermanas y hermanos cristianos o poetas que nos dirán que luchan desde el amor; por ende, el amor debe ser entendido de la siguiente manera:

- $\quad$ como un apetito por algo que se encuentra más allá de nosotros mismos, por una vida que no teme a la muerte, y que enfrenta los poderes de la muerte;

- $\quad$ desde una perspectiva de justicia, más allá de odios y miedos;

- $\quad$ como una realidad que puede ser encontrada en los lugares menos esperados, en los cambios concretos, de leyes, de perspectivas y formas de organización;

- $\quad$ como un sentimiento que ha estado presente en la historia y que continúa vigente;

- $\quad$ como un mecanismo que permite alcanzar una vida más justa a través de las luchas de las personas;

- $\quad y$, por último, como un conjunto de particularidades presentes en nuestra historia que nos permiten construir una serie de ideas de una comunidad, una nación o un continente que lleven a la dignidad tanto desde la perspectiva del "otro" como desde nuestro comprender, puesto que no somos hegemonías, ni moralidades. Somos también lo que no se borró, somos la ética que combatió los moralismos, así como los que no se han dejado dominar. 